\title{
Sobre o estudo da filosofia indiana ${ }^{1}$
}

\author{
Marcus Sacrini
}

Professor do Departamento de Filosofia da USP

1 Agradeço ao estimado amigo João Eduardo de O. Sita pela leitura atenta de versões anteriores deste texto e sugestões críticas que ajudaram a construir esta versão final.

\section{discurso 43}



"A Índia é maior que o mundo"

Jorge Luís Borges

Grande parte da formação acadêmica oferecida pelos departamentos de filosofia brasileiros está centrada na leitura crítica de obras filosóficas canônicas, de maneira que se espera amadurecer nos estudantes guiados por esse modelo a capacidade de reconhecer os principais movimentos argumentativos dos textos estudados, revelando, assim, os nexos de justificativas racionais por meio dos quais as teses filosóficas são construídas. Não pretendo aqui formular nenhum juízo de valor acerca desse modelo, mas apenas notar que o tipo de trabalho fomentado por ele (a reconstrução das reflexões filosóficas conforme a ordenação sistemática e racionalmente justificada de seus conceitos e teses) poderia acolher como tema não somente a produção de autores de alguns poucos países da Europa ocidental, mas também aquela de pensadores de outras partes do mundo. Assim, não haveria nenhum impedimento teórico grave em estender o escopo temático desse modelo formador, e isso porque existiram escolas filosóficas para além daquelas surgidas na Europa e que normalmente compõem o currículo formativo dos cursos de filosofia no Brasil.

É exatamente este ponto, a saber, que foram criadas escolas filosóficas fora daqueles países europeus comumente associados à filosofia (Grécia, Alemanha, França, Reino Unido e alguns poucos outros), o que exige esclarecimento. Não se trata aqui de apontar para departamentos de filosofia ou associações filosóficas que estudam e promovem, à sua maneira em muitas partes do mundo, a fenomenologia, a filosofia analítica ou quaisquer outras doutrinas criadas originalmente na Europa. Não importa discutir a presença da filosofia em outras partes do mundo nesse sentido óbvio. O que cumpre acentuar é que a filosofia não é um fenôme- 
no exclusivo daqueles países mencionados e só muito tardiamente divulgado para o resto do mundo. E, de fato, há evidências textuais consideráveis de que desde muito cedo na história (no período próximo àquele em que a filosofia se sistematizou na Grécia antiga), escolas filosóficas surgiram em territórios asiáticos e lá prosperaram por muitos séculos de modo relativamente autônomo ${ }^{1}$. Se isso estiver correto, então tais escolas poderiam ser incluídas entre os temas da formação acadêmica em filosofia, já que essa busca, ao menos em parte, oferecer um repertório mínimo acerca dos grandes temas filosóficos tais como elaborados pelos principais autores de diferentes épocas históricas. Por conseguinte, essa formação seria enormemente enriquecida ao se considerar de que maneira pensadores de diferentes partes do mundo por vezes se defrontaram com problemas semelhantes àqueles enfrentados pelos autores tradicionalmente estudados nos cursos de filosofia, ou mesmo como tais pensadores formularam novos problemas, cuja análise ampliaria por si só a compreensão do alcance e dos limites dos recursos reflexivo-racionais. No restante deste artigo, vou me limitar a mostrar a plausibilidade da tese de que a filosofia se desenvolveu em um contexto não europeu, aquele da Índia clássica (delimitado aqui como um período de produção cultural, iniciado por volta do século III a. C. e estendido até por volta do séc. XII d. C., nos territórios do subcontinente indiano e proximidades) ${ }^{2}$, deixando em aberto a possibilidade de que esforços semelhantes venham a ser realizados em relação a outras culturas e épocas.

\footnotetext{
1 Abstenho-me de tratar aqui o difícil problema de saber se essas escolas foram inspiradas pelo pensamento grego, que seria então a fonte originária da filosofia, ou se surgiram independentemente dele. Sobre esse ponto, cf. Bronkhorst 2001.

2 Há divergências sobre a datação dos períodos da história indiana bem como quanto à extensão precisa dos territórios sob domínio militar e influência cultural indiana. Para uma tentativa de história cultural dos territórios indianos tendo em vista o estabelecimento de escolas filosóficas, cf. Bronkhorst 2007. De minha parte, não pretendo propor nenhuma delimitação histórico-geográfica rígida, mas simplesmente esboçar um recorte cultural mínimo para tornar visível a produção filosófica clássica indiana.
} 
Antes de abordar as pretensas escolas filosóficas da Índia, é necessário propor alguns critérios de identificação da própria filosofia. Certamente não se trata de verificar a utilização do vocábulo "filosofia”, e sim de explicitar algumas de suas principais determinações conceituais. Com efeito, os indianos não dispunham da palavra "filosofia", e nem parecem tê-la adotado sistematicamente após o estabelecimento de contatos mais duradouros com a cultura grega, quando da invasão de Alexandre, por volta de 327 a. C. ${ }^{3}$. Importa notar que esse fato não é decisivo para o ponto em questão, pois nada impediria que o termo fosse usado erroneamente caso tivesse sido assumido, de maneira que a sua mera presença não garantiria de imediato a existência de uma filosofia indiana, bem como a sua ausência, assim creio, não implica a inexistência de um tipo de reflexão semelhante àquela intitulada desde a Grécia antiga de "filosofia".

Por sua vez, é notável que alguns gregos antigos chamaram certos homens que conheceram na Índia de "filósofos", fato revelador de que houve o reconhecimento de similaridades entre o que era feito por esses homens na Índia e a tradição filosófica grega ${ }^{4}$. Esse dado histórico pode servir de ponto de partida para a circunscrição daquelas determinações conceituais mínimas que legitimariam a atribuição do caráter filosófico a discursos produzidos na Índia clássica. Cabe então retomar, ainda que de forma rápida e geral, alguns dos principais componentes disso que cha-

$3 \mathrm{O}$ termo comumente usado pelas tradições brahmânicas para se referir às disciplinas que chamamos de filosóficas é "dar ana", traduzido como visão ou ponto de vista. Para uma discussão sobre a aproximação dos temos "dar ana" e "filosofia", cf. Prasad 2008, p. 30-2. Vale notar que mesmo em escolas não brahmânicas, tais como o budismo e o jainismo, e que não se definem como dar anas, pode-se também apontar a presença de concepções filosóficas.

4 Destaca-se o relato de Megasthenes (embaixador do rei Seleucus Nicator por volta do ano 300 A. C. em território indiano) intitulado Indica, do qual só restam passagens citadas por outros escritores. Para uma análise crítica desse relato, cf. Bosworth 1996. 
mei de tradição filosófica grega e verificar a sua atestação na produção cultural indiana. Quanto a esse ponto, menciono somente dois aspectos: em primeiro lugar, a filosofia grega se desenvolveu como discurso racional, que oferece justificativas lógicas para a sustentação de teses, afastando-se progressivamente das narrativas míticas ${ }^{5}$. Em segundo lugar, as discussões filosóficas não visavam meramente a construção de sistemas teóricos, mas também implicações diretas nas atividades práticas, sendo que um certo modo de viver era uma consequência esperada da atividade filosófica ${ }^{6}$.

Parece bastante provável que essas duas características tivessem um peso considerável no reconhecimento pelos gregos de alguns indianos como filósofos. No entanto, na sequência deste artigo, pretendo acentuar somente a justificativa racional como elemento característico do discurso filosófico, pois esse parece ser o principal aspecto que permite encontrar conexões entre as doutrinas modernas ou contemporâneas comumente chamadas de filosóficas e a filosofia antiga. A ênfase em consequências práticas constituintes de um modo de vida compõe um elemento marcante da filosofia antiga, em sua versão grega ou indiana ${ }^{7}$; porém, dificilmente essa ênfase permanece central na maior parte das filosofias europeias modernas e contemporâneas. As discussões filosóficas desses períodos tenderam a enfatizar consideravelmente o caráter conceitual dos problemas tratados, por meio de análises cada vez mais técnicas e especializadas ${ }^{8}$. Sob esse modelo de análise, as discussões filosóficas não envolvem necessariamente exercícios práticos para constituir um modo de vida específico. Por exemplo, nenhum pesquisador contemporâneo de ética dei-

5 Há uma extensa bibliografia sobre esse tema. Cf. p. ex., Vernant 1962, Frede e Striker 1999.

6 Sobre esse ponto, cf. Hadot 1995, 1998.

7 Para uma discussão acerca das finalidades práticas ligadas às reflexões dos autores indianos clássicos, cf. Mohanty 1995.

8 Em todo caso, o próprio Hadot buscou explicitar prolongamentos dos exercícios espirituais antigos em algumas concepções filosóficas modernas (cf. Hadot, 1995, p. 104-5, 295-8) e contemporâneas (Id., Ibid., p.392-407). 
xará de ser considerado um pesquisador ou filósofo por não agir eticamente no seu dia a dia, o que revela que a conexão, antes considerada intrínseca, entre reflexão teórica e modo de viver deixou de ser decisiva para a constituição da reflexão filosófica. Assim, a característica que fornece mais claramente o sentido de continuidade entre as filosofias moderna e contemporânea e a filosofia antiga é principalmente a articulação lógica do discurso, ou seja, a apresentação de justificativas racionais para a defesa de teses e sistematização de posições teóricas, e isso tendo em vista problemas conceituais amplos, que não podem ser decididos empiricamente. Entre tais problemas, menciono as questões sobre a natureza da realidade, sobre o acordo ou desacordo das categorias cognitivas e os objetos mundanos, sobre a legitimidade das normas éticas ou de padrões estéticos, entre muitas outras. Será por meio desse aspecto conceitual-argumentativo (de maneira a atestar alguma unidade entre o que se faz contemporaneamente sob o título de "filosofia" e o que os filósofos antigos ao menos em parte faziam) que considerarei o caráter filosófico de algumas escolas indianas de pensamento.

Ainda cabe descrever um pouco mais de perto a construção de posições filosóficas por meio da argumentação. Eu sugeri há pouco que os discursos ditos filosóficos são aqueles que se dedicam a analisar questões amplas, que não se decidem por verificação empírica e exigem uma refinada elaboração conceitual para que seus diversos elementos e articulações sejam paulatinamente explicitados e explorados criticamente. Por meio dessa análise, constituem-se concepções sistemáticas acerca dos temas tratados, as quais não são meras construções conceituais arbitrárias, já que é pela apresentação de razões que os proponentes de tais concepções pretendem mostrar que elas estão corretas e devem ser aceitas. O discurso filosófico almeja, dessa maneira, o convencimento racional; ele não se limita a oferecer quaisquer sistematizações conceituais acerca de temas não decidíveis empiricamente, mas sim sistematizações justificadas racionalmente. 
O caráter argumentativo do discurso filosófico obriga os autores que o exercem a ponderar sobre posições e argumentos alheios diante dos mesmos problemas. Quer dizer, não basta ao defensor de uma posição filosófica inventar quaisquer argumentos para suas teses a fim de tornálas imediatamente justificadas. Afinal, esses argumentos podem ser refutados por objeções ou contra-argumentos de partidários de outras posições. E somente argumentos resistentes a críticas advindas de outras concepções acerca dos temas em questão podem constituir a melhor resposta racional disponível até aquele momento. O gênero argumentativo está, assim, fortemente ligado a um contexto dialógico, de forma que os filósofos, a fim de exercer plenamente a vocação racional de seu discurso, devem responder minimamente às posições contrárias que também tentam se estabelecer racionalmente? ${ }^{9}$ Essa abertura ao embate crítico inerente à argumentação normalmente se concretiza, em termos bem gerais, da seguinte forma: de início, há uma defesa argumentada de teses acerca de um tópico em pauta, à qual se segue a formulação de objeções ou contra-argumentos por adversários, o que obriga o primeiro arguidor (ou seus partidários) a oferecer respostas, por vezes com um eventual aperfeiçoamento ou mesmo abandono das teses iniciais. Esse tipo de interação argumentativa é marcante no desenvolvimento das escolas filosóficas, que tendem a ser aperfeiçoadas no correr das gerações seja pela discussão entre os adeptos seja pelos debates com defensores de outras escolas. Por meio dessas discussões críticas, as sistematizações filosóficas atingem, ainda que no correr de várias gerações, um alto grau de coerência e abrangência ${ }^{10}$. Esse processo envolve também um aperfeiçoamento dos próprios padrões de justificação argumentativa, à medida que as relações inferenciais

9 Johnson (2000) defende esse ponto de modo bastante detalhado. Para uma análise crítica de alguns tópicos de sua teoria, cf. Hitchcock 2002.

10 Rescher (2001) oferece uma reflexão bastante elaborada sobre o desenrolar histórico da filosofia por meio de embates críticos. 
entre as sentenças vão sendo exploradas e sedimentadas em sistemas lógicos cada vez mais elaborados.

Sem dúvida, as obras canônicas normalmente estudadas na formação acadêmica brasileira em filosofia apresentam sistematizações conceituais justificadas racionalmente e inseridas em embates críticos com sistematizações rivais. Cabe agora mostrar que essa caracterização do discurso filosófico se aplica a textos produzidos na Índia clássica.

A Índia tem sido objeto de concepções estereotipadas já há séculos. Segundo algumas delas, os seus habitantes seriam portadores de uma cultura imemorial construída sobre uma sabedoria religiosa que perpassaria todos os domínios da vida comum. Os indianos formariam um povo centrado na religiosidade e guiado pelo misticismo, de modo que não se poderia encontrar ali sistemas de pensamento racional ${ }^{11}$. No entanto, ao menos desde o século XVIII, esforços sistemáticos de pesquisadores ligados a diversas áreas (linguística, história, filosofia, por exemplo) têm sido feitos para desmontar essas ideias simplificadoras, tornando visível a riqueza concreta da cultura indiana. É apenas um pequeno resultado do trabalho desses pesquisadores, a saber, a atestação de que houve escolas filosóficas bastante elaboradas na Índia clássica, que retomarei aqui.

Uma das maiores dificuldades para superar essas concepções estereotipadas é que de fato as religiões tiveram um papel de destaque na organização da vida social na Índia clássica. É verdade então que a maioria das escolas indianas de pensamento estavam ligadas a doutrinas religiosas (brahmânicas, budistas ou jainistas), e pode-se verificar em muitas delas pressupostos oriundos dessas 
doutrinas que são pouco questionados ou nem mesmo considerados criticamente. No entanto, é imprescindível destacar que, nesse contexto, assim como na Idade Média europeia, a ordenação de grande parte das relações sociais conforme preceitos de origem religiosa não impediu o florescimento de investigações guiadas por normas racionais (Gilson 1988). Para corroborar esse ponto, retomo aqui o fato de que desde muito cedo na Índia autores preocuparam-se em estudar as inferências lógicas, de maneira a explicitar e fixar padrões argumentativos aceitáveis racionalmente. Destaca-se a escola brahmânica Ny ya, cujo texto basilar, Nyāyasūtra (Aforismos sobre lógica, escrito por volta do séc II d. C.), já considerava a ideia de que conclusões discursivamente aceitáveis deviam derivar de razões, embora ainda não propusesse uma recensão clara de formas válidas de conexão inferencial.

No correr dos séculos, diversos autores se esforçaram para sistematizar a estrutura formal de inferências válidas, dando sequência às reflexões contidas no Nyāya-sūtra. Um texto importante para o avanço dessa sistematização é Nyāya-bhașya (Comentário à lógica - escrito por volta do séc $\mathrm{V}$ d. C.), um dos primeiros comentários sobre o Nyāya-sūtra, em que a análise de padrões inferenciais válidos é bastante refinada, mesmo sem ainda isolar claramente os laços formais entre as proposições, os quais são tratados como uma espécie de relação causal. A delimitação precisa das estruturas puramente formais de ao menos certas inferências silogísticas foi realizada principalmente pelos autores budistas Dign ga e Dharmakīti (respectivamente dos séculos VI e VII d. C.). Essa contribuição de autores de diferentes filiações religiosas para o aperfeiçoamento da lógica torna visível o esforço de diversas escolas de pensamento para estabelecer padrões inferenciais tendo em vista tanto a compreensão da produção de conhecimento quanto o exercício mais efetivo dos raciocínios nas disputas teóricas de então. Constitui-se, assim, uma história da lógica, ou seja, um trabalho sistemático de muitas gerações tendo em vista a explicitação das regras racionais para a validação de teses, o que 
por si só já desmente as concepções que na Índia clássica só vislumbram misticismo ${ }^{12}$.

Até aqui simplesmente notei que o predomínio das doutrinas religiosas na organização da vida social na Índia clássica não impediu a teorização acerca do discurso racional. Vale notar, agora, que, embora sejam exceções, houve escolas filosóficas que pouco ou nada deveram a essas doutrinas religiosas. $\mathrm{O}$ exemplo mais radical é a escola Cārvāka (esboçada já por volta do séc. V a. C. e que floresceu, em diferentes níveis de sistematização, até por volta do séc. XII d. C.), cujos partidários negavam a existência de qualquer princípio anímico separado do corpo. Dessa forma, os Cārvāka rejeitavam a continuidade da existência após a morte e, por conta disso, apontavam a inutilidade de ritos sacrificiais religiosos. Suas discussões filosóficas (acerca da natureza da consciência, dos componentes da matéria, entre outros tópicos) avançavam por inferências lógicas, sem apelo à autoridade religiosa ${ }^{13}$.

Outro exemplo notável de proposta teórica sustentada argumentativamente está contido no texto Mokșopāya (Meios para a libertação $)^{14}$, que foi provavelmente o núcleo em torno do qual a longa compilação de narrativas denominada Yogavāsiștha ${ }^{15}$ foi posteriormente organizada ${ }^{16}$. O autor do Mokșopāya apresenta a sua posição conceitual (negação da existência objetiva do mundo)

12 Para uma leitura introdutória da história da lógica na Índia, cf. Gillon 2011. Para análises mais detalhadas das concepções lógicas da escola $\mathrm{Ny}$ ya antiga até o filósofo Ga ge a (por volta do séc. XIV d. C.) e comparações com os autores budistas mencionados, cf. Ganeri 2001. E para uma avaliação crítica da obra de Ganeri, cf. Patil 2010. 13 Para uma discussão detalhada acerca dos fragmentos da doutrina Cārvāka disponíveis, bem como das teses neles contidas cf. Bhattacharya 2002.

${ }_{14}$ Escrito provavelmente entre os séculos IX e X d. C.

15 Esse título pode ser traduzido como "O Yoga de Vasistha”, entendendo por yoga um conjunto de disciplinas psicossomáticas e espirituais tendo em vista a libertação do sofrimento. Nesse livro, Vasistha é um sábio que ensina vários temas a um jovem príncipe chamado Rama. Doravante citado como YogV.

16 No próprio Yogavāsiștha o Mokșopāya é associado a uma sabedoria revelada; mas essa narrativa posterior em nada altera o caráter argumentativo do texto em questão (Slaje 1994). 
como sendo claramente baseada em inferências racionais ${ }^{17}$. De modo simplificado, o argumento central ali defendido é o seguinte: de início, admite-se que "não há efeito de algo que não tenha causa" (YogV 6.94.63, apud Slaje 1994, p. 260), o que significa que tudo o que existe deve ser derivado de causas também existentes. Em seguida, defende-se que "o mundo não é efeito do que quer que seja, pois ele não tem causa” (YogV 6.95.17ab, apud Id., Ibid.,), o que permite extrair a conclusão de que o mundo não existe (Ibid.). A razão oferecida para a asserção de que o mundo não tem causa é um apelo a uma crença tradicional, a saber, que há destruições periódicas nas quais o universo inteiro é aniquilado, e às quais se seguem recriações do mundo. Dado que cada aniquilação cósmica é completa, não resta nada que pudesse ser causa efetiva do mundo e a ele atribuísse existência. Como explicar então o aparente ser do mundo? Para além dessas repetidas destruições cósmicas, há somente Brahma, a consciência pura e imutável (Cf. YogV 3.2.36-7, apud Slaje 1994, p. 199-200). A realidade fenomenal não é senão um tipo de imaginação dessa consciência imutável, de maneira que, em si mesmo, o mundo não porta nenhuma substancialidade.

Apesar da admissão clara de um elemento religioso na discussão acerca do ser do mundo, importa notar que o esforço global do autor do Mokṣopāya é apresentar justificativas encadeadas racionalmente para a conclusão em vista, e não recorrer a intuições místicas acerca de Brahma ${ }^{18}$. Esse tipo de esforço pode ser notado em textos de várias escolas indianas. Por exemplo, quatro dos darśanas - Sāṃkhya, Vaiśeșika, Yoga, além do já mencionado

17 "Mesmo quando composto por um ser humano, um tratado deve ser aceito se ele ensina com base em argumentos [yukti]. Por outro lado, o resto deveria ser abandonado mesmo se vem dos 'videntes' [rși]" (YogV 2.18.2, in Slaje 1994, p. 167). É notável aqui o descrédito da sabedoria obtida por vidência mística em prol da argumentação, a qual mesmo a pessoa comum pode exercer.

18 Vou voltar a esse tópico do papel das intuições místicas para as tradições filosóficas indianas. 
Ny ya - aceitam a autoridade dos Vedas (textos sagrados brahmânicos) e assimilam, em maior ou menor grau, elementos dogmáticos em seu sistema. Porém, o principal método para a apresentação e defesa de teses nos textos dessas escolas não é o apelo a tais textos, e sim a construção de cadeias argumentativas.

Por fim, é inegável que algumas escolas indianas de pensamento atribuem um papel central à autoridade religiosa. Exemplos conhecidos são Pūrva Mīmāṃs e Vedānta (também conhecido como Uttarā Mīmāṃsā), darśanas que se dedicam em grande medida a comentar os textos védicos, assimilando mais elementos religiosos do que os darśanas mencionados no parágrafo anterior. Contudo, mesmo no interior dessas duas escolas, houve esforços para elaborar procedimentos hermenêuticos para a interpretação de textos sagrados, de maneira a construir análises racionais do legado religioso.

Por exemplo, Śankara (séc. VIII-IX d. C.), um dos expoentes do Vedānta, e seu discípulo Sureśvara (mesmo período) ${ }^{19}$ se utilizam do método anvayavyatireka ("presença-ausência" ou "continuidade-descontinuidade") para interpretar textos védicos sagrados. Por meio desse método, busca-se estabelecer qual o sentido de certos termos ao explicitar os seus referentes. A explicitação correta dos referentes se dá pelo contraste entre a presença e a ausência de possíveis elementos significados pelos termos em pauta. Ao tornar visível qual elemento está continuamente presente, estabelece-se o referente do termo e, por conseguinte, esclarece-se seu sentido. É assim que esses autores tentaram interpretar sentenças religiosas consideradas centrais nos textos védicos, tais como "tat tvam asi"20 ("tu és isso"), entendendo por "isso" (conforme reza o próprio texto sagrado) o ser absoluto. Uma das condições para a inteligibilidade desse juízo de identidade é discriminar

${ }_{19}$ Cf. Upadeśasāhasrī [Mil ensinamentos], verso XVIII (texto de Śañkara) e Naișkarmyasiddhi [A demonstração do não agir], verso IV, 22 (texto de Sureśvara). 20 Cf. Chandogya Upanishad, 6.8.7. 
qual o sentido do pronome "tu" (com o qual o leitor identifica o seu próprio eu), associado ao ser absoluto. Servindo-se do critério da presença contínua para determinar o referente, descartam-se o corpo e mesmo o intelecto como possíveis respostas, já que há situações (por exemplo, sonhos) em que o sujeito pode não ter a experiência do próprio corpo ou de suas faculdades cognitivas, mas nas quais a consciência de si permaneceria. É essa consciência que persiste sem variações nas mais diferentes experiências fenomenais (e que por isso mesmo se distingue dos componentes da personalidade concreta, mutáveis) que por fim é reconhecida como o sujeito idêntico ao ser absoluto ${ }^{21}$.

Essa é apenas uma reconstrução simplificada de uma técnica hermenêutica empregada por partidários de uma das escolas Vedānta, mas suficiente para confirmar que mesmo ao lidar com textos sagrados (cuja autoridade não se trata de questionar), alguns autores indianos formularam esquemas inferenciais complexos, longe de se limitar a uma repetição acrítica de dogmas ${ }^{22}$. E de maneira geral, os diferentes exemplos propostos nesta seção almejam mostrar que escolas centradas em discussões racionais se constituíram na Índia clássica. É preciso então admitir que ocorreu aí a formação de discursos racionais que visavam estabelecer suas teses acerca de questões conceituais amplas (acerca da natureza da realidade e do eu, acerca do instrumental epistêmico e seus limites etc.) pela elaboração de posições argumentadas.

Cabe aqui acentuar um aspecto marcante do contexto cul-

21 Para uma interpretação mais detalhada desse trecho védico e uma exposição geral dos recursos hermenêuticos das escolas Mīmāṃsā, cf. Hiriyanna 1949, Satchidanana Murty 1993, Halbfass 1991 e Comans 2000.

22 Vale notar que essa técnica já era utilizada, embora de forma menos elaborada, como estratégia argumentativa autônoma para estabelecer o caráter específico da consciência, independentemente de referências a textos sagrados. É o que fica claro, por exemplo, no Vaiśeșika Sütra (Aforismos sobre a diferenciação, texto provavelmente anterior ao Nyāya-sūtra) III, 2, 9, segundo o qual o eu pré-individual pode ser desvelado devido à separabilidade dos referentes da palavra "eu", sem apelo à autoridade religiosa. Sobre esse ponto, cf. Halbfass 1991, p. 166. 
tural indiano responsável por fomentar o florescimento dos discursos racionais. Os representantes das diferentes escolas indianas de pensamento comumente se enfrentavam em discussões ou debates críticos, os quais foram promovidos pelas cortes de muitas regiões do país em diferentes períodos históricos. Esses debates tiveram um papel central para a sedimentação das tradições filosóficas dali (Bronkhorst 2006). Afinal, conforme exposto na seção anterior, sob o crivo crítico dos adversários, os autores se obrigam a aperfeiçoar suas posições (ao responder a tentativas de refutação e antecipar objeções), resultando daí sistemas filosóficos cada vez mais coerentes e elaborados. Além disso, a disseminação dos debates revela que as doutrinas filosóficas na Índia clássica não eram um conhecimento esotérico, mas um dado cultural disponível fora do círculo dos adeptos, de modo que os autores aperfeiçoavam sua própria posição conceitual em contraste com posições alheias acerca dos mesmos temas ${ }^{23}$. Dessa forma, em meio a um contexto social em que debates entre partidários de diferentes escolas eram comuns, várias concepções filosóficas se estabeleceram guiadas por restrições racionais, o que permite circunscrever na Índia clássica uma história da filosofia, no sentido de um desenrolar de posições teóricas ordenado conforme a lógica interna do oferecimento de razões e contrarrazões, lógica irredutível a uma mera veiculação de dogmas ou mesmo à expressão de experiências místicas sobre-humanas.

Há aqui sem dúvida mais uma faceta a se superar daquelas ideias simplificadoras, a saber, que as teses difundidas pelos filósofos indianos, porque muitas vezes entrelaçadas a propostas de

23 Mais para o final do período clássico indiano, o conhecimento das doutrinas adversárias, necessário para obter sucesso na confrontação entre as diferentes escolas, fomentou abordagens filosóficas inclusivistas, segundo as quais as doutrinas concorrentes exprimiriam diferentes estágios de compreensão passíveis de subordinação à filosofia defendida por tais abordagens, as quais veiculariam uma verdade absoluta. Trata-se de estratégias reconhecidas em alguns autores jainistas e na escola Advaita Vedānta (Halbfass 1988, p. 351 ss.). 
formas de vida libertadoras de todo sofrimento existencial, devem ter surgido como expressão de atividades ou exercícios espirituais ligados a essas formas de vida. Aqui é preciso distinguir o modo de vida e seus exercícios como desiderato intrínseco à reflexão filosófica e como fonte de justificativas dessa própria reflexão. Essa última função é bem menos comum do que as visões estereotipadas acerca da cultura indiana sugerem. Quero dizer que a maior parte das teses defendidas pelos filósofos indianos em seus embates críticos não era apresentada como oriunda de revelação mística ligada a experiências meditativas. É verdade que diferentes escolas indianas de pensamento propõem exercícios meditativos de ascese espiritual, mas isso não quer dizer que as experiências geradas por tais exercícios são a fonte legitimadora das teses filosóficas. Pelo contrário, várias decisões teóricas centrais nas doutrinas indianas são embasadas por argumentos, e muitas vezes é com base nessas decisões argumentadas que se justificam as práticas ou exercícios ascéticos.

Por exemplo ${ }^{24}$, sabe-se que diferentes interpretações conceituais de uma doutrina de origem religiosa sustentam práticas meditativas específicas em vigor na Índia clássica. A doutrina em questão é aquela segundo a qual os atos dos indivíduos no decorrer das suas vidas são decisivos para determinar as circunstâncias do seu renascimento ou reencarnação (não distingo esses termos aqui). Trata-se aqui da doutrina do karma, herdada por muitos pensadores como um dogma inquestionável, mas que recebeu diversas interpretações teóricas. A aspiração mais elevada daqueles que partilhavam dessa doutrina não era obter um renascimento em condições agradáveis, mas romper com a sucessão interminável de renascimentos, garantindo, desse modo, a libertação final do existir encarnado. Para alcançar esse fim, diferentes compreensões do funcionamento do karma conduziram a práticas medita-

24 Para uma análise detalhada desse exemplo, cf. Bronkhorst 1998, 2011. 
tivas bastante específicas. Por exemplo, jainistas antigos julgaram que todos os atos físicos e mentais (independentemente de ser ou não virtuosos) geram uma cadeia de efeitos cujo resultado é o renascimento. Para evitar tal consequência, é necessário então evitar qualquer tipo de ato. Dessa maneira, a libertação só pode ser obtida se se pratica uma imobilização perfeita do corpo e da mente até a morte. Espera-se que por esse método nenhuma consequência kármica seja produzida, e que aquelas geradas antes de o praticante atingir a imobilidade tenham seus efeitos exauridos durante o tempo em que permanecer imóvel.

Por sua vez, muitas escolas brahmânicas também partilharam, ainda que não inicialmente, da doutrina da reencarnação devido ao karma. No entanto, nelas, interpreta-se que quem age, produzindo consequências kármicas, é a personalidade ordinária. Haveria, para além dela, o verdadeiro eu, diferente de todos os atos mundanos porque essencialmente imutável. Sob essa interpretação, as práticas meditativas sugeridas não eram de imobilização total, e sim de desidentificação com o eu mundano a fim de revelar o eu supremo, desde sempre livre do ciclo de reencarnações, revelação que poderia ser alcançada em vida. E ainda há aqui diferentes possibilidades de interpretação das relações entre o eu imutável e o eu fenomenal. Por exemplo, a doutrina Sāṃkhya prega um dualismo ontológico entre o eu imóvel e o domínio fenomenal; já as escolas Advaita Vedānta constroem interpretações monistas, segundo as quais somente o eu supremo existe verdadeiramente, sendo que a multiplicidade fenomênica, em última instância, é ilusória.

As escolas budistas oferecem ainda uma terceira linha interpretativa da doutrina do karma, segundo a qual não são os atos por si sós que determinam os renascimentos, mas o desejo (em sentido amplo), que está por trás de alguns deles. Assim, é preciso cessar não os atos por inteiro, como propunham os jainistas, mas extinguir o desejo que opera na sua formação. A meditação ensinada pelos budistas, por conseguinte, não almeja a imobilização 
nem o conhecimento de um verdadeiro eu, mas sim a extinção do desejo, responsável pelas consequências kármicas que prendem os indivíduos em um ciclo interminável de renascimentos.

Esses três exemplos (apresentados aqui de modo bastante esquemático, é verdade) permitem notar que as experiências meditativas, um aspecto prático relevante nas tradições religiosas indianas, dependem de interpretações conceituais para serem sistematizadas e ritualizadas, e de forma geral não são a fonte de justificação das posições teóricas assumidas pelas escolas filosóficas. A prática meditativa, longe de anteceder e guiar as compreensões teóricas, supõe determinações teóricas precisas, as quais foram intensamente debatidas na Índia clássica. Há mesmo alguns autores indianos clássicos tais como Ramajuna (por volta do séc. XII d. C.) e antes dele Kumārila (séc. VII, consolidador do darśana Pūrva-Mīmāṃsā), que rejeitavam as experiências místicas como fonte de autoridade. Outros, tais como Bhart hari (por volta do séc. V d. C.), aceitavam a validade de algumas variantes de intuição suprassensível, mas as consideravam como derivadas de faculdades disponíveis a todas as pessoas e não como experiências portadoras de uma autoridade incorrigível ${ }^{25}$. Dessa forma, parece correto afirmar que as escolas de investigação racional florescidas na Índia clássica não se centraram na expressão de experiências místicas suprassensíveis, e sim na sistematização de posições teóricas justificadas argumentativamente.

É importante acentuar que nem todo o pensamento indiano se moldou por meio desse processo de sistematização racional e que nem todas as escolas filosóficas permaneceram com o mesmo vigor racional durante a sucessão de gerações que as defenderam. Aqui pretendi somente romper com aquela visão estereotipada segundo a qual haveria um misticismo envolvendo todas as pro-

25 Para mais detalhes acerca da posição desses e outros autores acerca das experiências místicas, cf. Chakrabarti 1997. 
duções culturais da Índia clássica. Mas de modo algum pretendo incentivar uma concepção inversa, também fantasiosa, de que todo pensamento produzido na Índia clássica era filosófico, de que a filosofia lá foi incansavelmente disseminada e dominou todos os domínios culturais etc. Apenas julgo inegável a existência de escolas de investigação racional na Índia. Contudo, essas escolas começaram a existir em certo momento e sob determinadas circunstâncias históricas, fortaleceram-se e enfraqueceram-se em outros momentos, sob outras circunstâncias. Para evitar que simplesmente se troque de estereótipo em relação à produção cultural indiana, faz-se necessário atentar para os estudos acadêmicos rigorosos centrados em dados históricos concretos, por meio dos quais se pode revelar paulatinamente a real complexidade da vida cultural na Índia clássica.

Quanto às obras filosóficas indianas, essa exigência de pesquisas rigorosas menos generalistas aponta para um tratamento mais detalhado dos tópicos até aqui exemplificados. Por exemplo, eu acentuei a existência de escolas filosóficas na Índia clássica, e isso porque a filiação a tradições já existentes, e não a produção de sistemas filosóficos independentes, parece ter sido a atitude mais comum dos pensadores indianos. Mas a partir desse dado inicial seria necessário, a fim de obter uma apreensão mais precisa dos temas e argumentos apresentados, especificar quais foram os autores que criaram ou consolidaram as escolas, quando isso foi feito e sob quais circunstâncias. Além disso, seria necessário individualizar as contribuições teóricas às escolas, de maneira a explicitar as problematizações específicas dos autores de diferentes gerações a elas filiados ${ }^{26}$. Falar de escolas filosóficas indianas ainda é tão vago quanto seria, no caso da filosofia europeia, mencionar a tradição empirista, a tradição racionalista ou o idealismo alemão. Sem dúvida, essas referências generalistas permitem distinguir problemas 
filosóficos comuns em longos períodos e traços metodológicos partilhados por muitos autores em sua busca por respostas conceituais coerentes e argumentadas, mas, por outro lado, ela oculta particularidades marcantes do projeto filosófico de cada autor no interior de uma mesma escola. Que se considerem, por exemplo, as diferenças entre o racionalismo de Descartes e Leibniz ou entre o empirismo de Berkeley e Locke para ter uma ideia clara do que quero dizer. A especificidade teórica desses autores só pode ser trazida à luz por meio de estudos minuciosos das obras de cada um deles. Da mesma forma, para obter uma compreensão menos simplista dos darśanas ou demais escolas filosóficas indianas é preciso considerá-las não como blocos teóricos anônimos, que defendem de modo atemporal concepções fixas, mas como empreendimentos críticos construídos paulatinamente por autores confrontados com circunstâncias concretas. Somente nesse nível de detalhe, que não é senão aquele em que normalmente se estuda a produção filosófica europeia em nossos cursos acadêmicos, poderão os estereótipos sobre as escolas indianas de pensamento ser superados de forma convincente.

\section{IV}

Se é verdade que concepções filosóficas foram elaboradas na Índia clássica, então elas poderiam ser integradas à grade curricular da formação brasileira em filosofia. O mesmo tipo de estudo acadêmico das escolas filosóficas europeias antigas, medievais e posteriores, a saber, a reconstrução dos movimentos argumentativos por meio dos quais as teses defendidas se ordenam em concepções sistemáticas, pode perfeitamente ser aplicado a muitos textos produzidos na Índia clássica. É verdade que talvez haja muitos obstáculos para a inclusão do estudo dos autores e escolas indianas em nossa formação acadêmica de filosofia (dificuldades para compreensão da língua e do contexto histórico em que as obras foram produzidas, ausência de profissionais competentes em nos- 
sas instituições etc.). Porém, sugiro que não se mencione como um desses obstáculos o pretenso fato de que nunca houve filosofia na Índia, já que, como espero ter mostrado, trata-se meramente de uma opinião falsa. No sentido crucial de desenvolvimento de escolas centradas em discussões argumentadas sobre problemas não decidíveis empiricamente (sentido que chega mesmo a garantir a unidade entre os diversos tipos de filosofia praticados em mais de dois milênios nos territórios ocidentais), a filosofia faz parte da herança cultural da Índia.

\section{Referências}

BHATTACHARYA, R. "Cārvāka fragments: a new collection", Journal of Indian Philosophy, Vol.30, n.6, 2002, p.597-640.

BOSWORTH, A. B. “The historical setting of Megasthenes' Indica", Classical Philology, Vol. 91, n. 2, 1996, p. 113-127.

BRONKHORST, J. Greater Magadha. Studies in the culture of early India. Leiden: Brill, 2007. Karma. Honolulu: Univ. of Hawaii Press, 2011. "Pourquoi la philosophie existe-t-elle en Inde?". In: (ed.) La rationalité en Asie/ Rationality in Asia. Études de Lettres, n. 3, 2001, p.7-48.

"Self and meditation in Indian Buddhism". In: VV.AA. International Conference on Korean Son Buddhism. Seoul: Kobulch'ongnim Much'asonhoi Organizing Committee, 1998, p. 141-159.

"The context of Indian philosophy". In: WADA, T. (ed.). Conflict between Tradition and Creativity in Indian philosophy: Text and Context; Proceedings of the 7th International Conference, Studies for the Integrated Text Science. Nagoya: Graduate School of Letters, 2006, p. 9-22. 
CHAKRABARTI, A. "Rationality in Indian philosophy". In: Deutsch, E., Bontekoe, R. (eds.). A companion to world philosophies. Oxford: Blackwell, 1997, p. 259-278.

COMANS, M. The method of early Advaita Vedānta. New Delhi: Motilal Banarsidass, 2000.

FREDE, M., STRIKER, G. (eds.) Rationality in Greek thought. Oxford: Oxford Univ. Press, 1999.

GANERI, J. Philosophy in classical India. The proper work of reason. New York: Routledge, 2001.

GILSON, É. La philosophie au Moyen Âge. Paris: Payot, 1988.

GILLON, B. "Logic in classical Indian philosophy", in Zalta, E. (ed.). The Stanford encyclopedia of philosophy. <http://plato. stanford.edu/archives/sum2011/entries/logic-india/>

HADOT, P. Études de philosophie ancienne. Paris: Les Belles Lettres, 1998.

Qu'est-ce que la philosophie ancienne? Paris: Gallimard, 1995.

HALBFASS, W. India and Europe. An essay in understanding. Albany: SUNY Press, 1988.

Tradition and reflection. Explorations in Indian thought. Albany: SUNY Press, 1991.

HIRIYANNA, M. The essentials of Indian philosophy. London: Allen und Unwin, 1949.

HITCHCOCK, D. "The practice of argumentative discussion", Argumentation, Vol. 16, n.3, 2002, p. 287-298.

JOHNSON, R. Manifest rationality: a pragmatic theory of argument. New York: Routledge, 2000.

KRISHNA, D. Indian philosophy - a counter-perspective. Delhi: Osford Univ. Press, 1996.

MOHANTY, J. "Theory and practice in Indian philosophy", Australasian journal of philosophy, Vol. 73, n.1, 1995, p.1-12.

PATIL, P. "History, philology, and the philosophical study of sanskrit texts”, Journal of Indian Philosophy, Vol. 38, n. 2, 2010, p. 163-202. 
PRASAD, R. A conceptual-analytic study of classical Indian philosophy of morals. New Delhi: PHISPC, 2008.

RESCHER, N. Philosophical reasoning: a study in the methodology of philosophizing. Oxford: Wiley-Blackwell, 2001.

SATCHIDANANDA MURTY, K. Vedic hermeneutics. Delhi: Motilal Barnasidass, 1993.

SEDLAR, J. W. India and the Greek world. A study in the transmission of culture. New Jersey: Rowman and Littlefield, 1980. SLAJE, W. Vom Mokṣopāya-Śāstra zum YogavāsișthaMahārāmāyana. Philologische Untersuchungen zur Entwicklungs- und Überlieferungsgeschichte eines indischen Lehrwerks mit Anspruch auf Heilsrelevanz. Wien: ÖAW, 1994.

VERNANT, J. P. Les origines de la pensée grecque. Paris: PUF, 1962. 
